\title{
INFLUÊNCIA DA VELOCIDADE DE TRATOR E SEMEADORA DE PRECISÃO NA IMPLANTAÇÃO E PRODUTIVIDADE DA CULTURA DO MILHO VERDE
}

\author{
Delorme Corrêa Júnior ${ }^{1}$, Ricardo Ferreira Garcia², Carmen Maria Coimbra Manhães ${ }^{3}$, Pablo Pereira Corrêa \\ Klaver $^{4}$, José Francisco Sá Vasconcelos Júnior ${ }^{5}$
}

\begin{abstract}
RESUMO
O objetivo deste trabalho foi avaliar o desempenho de uma semeadora de precisão na implantação e caracteres produtivos da cultura do milho. Avaliou-se o desempenho da semeadora e produtividade da cultura. Foi utilizado um trator Massey Ferguson modelo MF 283 4x2 TDA e semeadora de precisão modelo SEED LINE. Foi regulado para distribuir 5,9 sementes. $\mathrm{m}^{-1}\left(65.000\right.$ plantas.ha $\left.^{-1}\right)$, com $5 \mathrm{~cm}$ de profundidade e $90 \mathrm{~cm}$ entre linhas. $\mathrm{O}$ experimento foi montado em blocos casualizados, com três velocidades e quatro repetições, totalizando 12 unidades amostrais. As velocidades de operação foram 7,0; 5,5 e 4,5 km.h. $\mathrm{h}^{-1}$. Observou-se que a velocidade influenciou na velocidade periférica do disco dosador de sementes, número de sementes, espaçamento entre sementes, comprimento e largura da folha. Consequentemente, a maior velocidade periférica do disco dosador interferiu no número de sementes $(3,9)$ e espaçamento entre sementes na maior velocidade. Para as condições experimentais recomenda-se a utilização da velocidade de trabalho de $4,5 \mathrm{~km} \cdot \mathrm{h}^{-1}$.
\end{abstract}

Palavras-chave: produção, precisão de semeadura, Zea mays L.

\section{ABSTRACT \\ INFLUENCE OF TRACTOR SPEED AND PRECISION SEEDER IN PRODUCTIVITY AND DEPLOYMENT OF CULTURE OF GREEN MAISE}

The aim of this study was to evaluate the performance of a precision seeder on deploying and productive characters of the tillage corn. It was evaluated parameters of sower and the productivity of the culture. It was used a tractor Massey Ferguson MF $2834 \times 2$ model TDA and precision seeder model SEED LINE. It was adjusted to 5.9 distributing seeds per meter $\left(65.000\right.$ plants.ha $\left.{ }^{-1}\right)$, with $5 \mathrm{~cm}$ deep and $90 \mathrm{~cm}$ between rows. The experiment was a randomized block with three speeds and four replications, totaling 12 sampling units. For the operating speeds used were 7.0, 5.5 and 4.5 $\mathrm{km} \cdot \mathrm{h}^{-1}$. The results showed that the velocity affected on the peripheral speed of the dosimeter seeds, number of seeds, seed spacing, length and width of the sheet. Consequently, the fastest peripheral speed of the disc dosimeter affect the number of seeds ( 3.9 seeds) and seeds spacing at fastest speed. For the experimental conditions recommended to use the forward speed of $4.5 \mathrm{~km} \cdot \mathrm{h}^{-1}$.

Keywords: production, precision in sowing, Zea mays L.

Recebido para publicação em 01/12/2012. Aprovado em 24/06/2013.

1 - Eng. Agrônomo, Mestre. Doutorando em Engenharia Agrícola, UFLA, Lavras, MG. delormeminas@hotmail.com.

2 - Eng. Agrícola, Doutor. Professor do Laboratório de Engenharia Agrícola, UENF, Campos dos Goytacazes, RJ. garcia@uenf.br

3 - Eng. Agrônoma, Mestre. Doutoranda em Produção Vegetal, UENF, Campos dos Goytacazes, RJ. carmenmanhaes@yahoo.com.br

4 - Eng. Agrônomo, Doutor. Professor da Escola Técnica Estadual Agrícola Antônio Sarlo, Campos dos Goytacazes, RJ. pablo@uenf.br

5 - Eng. Agrônomo, Mestre. Doutorando em Produção Vegetal, UENF, Campos dos Goytacazes, RJ. jrferrete@hotmail.com 


\section{INTRODUÇ̃̃O}

O milho (Zea mays L.) é uma das principais culturas, com grande importância econômica e social no mundo. No Brasil a cultura vem aumentando sua produtividade a cada ano e para a safra 2012/2013 estima-se que a produtividade chegue a $4920 \mathrm{~kg}$. ha- ${ }^{-1}$, de acordo com o primeiro levantamento da safra brasileira de grãos 2012/13 liberado em outubro de 2012 pela CONAB (2012).

De acordo com a Associação Brasileira de Normas Técnicas - ABNT (1994), as semeadoras são classificadas segundo a forma de distribuição de sementes, como semeadoras de precisão e de fluxo contínuo. As semeadoras de precisão são máquinas que distribuem as sementes no sulco de semeadura, uma a uma ou agrupadas, em linhas e em intervalos regulares de acordo com a densidade de semeadura estabelecida. No caso da cultura do milho verde se exige que se tenha distribuição uniforme de sementes para que se tenha um bom estande de plantas que irá influenciar em uma produtividade esperada.

Para Silva et al. (1993), dentre os diversos fatores que interferem no estande de plantas e, consequentemente, na produtividade é a velocidade de operação da máquina no campo. Portanto, é de extrema importância a realização de trabalhos que visam à obtenção de respostas relacionadas ao desempenho de máquinas para semeadura.

A velocidade periférica do disco dosador de sementes é um dos fatores que pode interferir no estande de plantas (distribuição de sementes). Segundo Mantovani et al. (1999); Vale et al. (2008), velocidades acima de $0,32 \mathrm{~m} \cdot \mathrm{s}^{-1}$ podem prejudicar a uniformidade de distribuição, pois, com essas velocidades, as sementes não têm tempo suficiente para preencher todos os furos do disco dosador, com isso haverá falhas na distribuição. Já velocidades abaixo de $0,29 \mathrm{~m} \cdot \mathrm{s}^{-1}$ favorecem o preenchimento total dos furos do disco dosador, e somente podem ser problemáticas quando as sementes tiverem tamanhos muito menores que os furos do disco. Com isso, os furos do disco dosador podem capturar duas ou mais sementes, ocorrendo o surgimento de duplos no ato de semeadura - duas ou mais sementes depositadas com um espaço menor entre elas do que o espaço normal - essas plantas competirão entre si e o seu crescimento, desenvolvimento e produção serão afetados por essa razão.

Cultivares ideais para produção de milho verde devem apresentar espigas grandes e com bom empalhamento, o que confere à espiga maior proteção contra o ataque de pragas, que depreciam o produto; os grãos devem ser do tipo dentado, com alinhamento retilínio e ter, preferencialmente, cor amarelo-creme; o endurecimento dos grãos deve ser relativamente lento; o pericarpo deve ser fino, pois quanto menor sua espessura, maior a maciez do grão após cozimento (Pereira Filho et al., 2003).

Para a produção de espigas verdes, o $\mathrm{N}$ tem sido responsável pelo aumento do seu rendimento, sendo seu efeito influenciado, também, por outros fatores, como genotípicos e ambientais. Trabalhos têm demonstrado o efeito da adubação nitrogenada sobre a produtividade de espigas para consumo verde. Cardoso et al. (2010) verificaram que a adubação nitrogenada propiciou espiga verde por planta mais pesada, com peso máximo por espiga com palha de $445 \mathrm{~g}$ e de $298 \mathrm{~g}$ para espiga sem palha.

Conforme Rocha (2008), na avaliação das características agronômicas de cultivares para milho verde, as mais utilizadas são: número e peso de espigas comerciais empalhadas; peso de espigas comerciais despalhadas; percentagem, diâmetro e comprimento de espigas comerciais; tempo de comercialização; florescimento masculino e altura de plantas.

O objetivo do trabalho foi avaliar a influência da velocidade de trabalho de um trator e semeadora de precisão em operação de semeadura de milho no desempenho do conjunto mecanizado e produtividade da cultura do milho verde.

\section{MATERIAL E MÉTODOS}

O experimento foi realizado no município de Mimoso do Sul, ES, mais precisamente às margens do rio Mimoso no sul do Estado do Espírito Santo fazendo divisa com o norte do Estado do Rio de Janeiro.

A avaliação foi realizada em sistema convencional e a área foi preparada com uma aração, realizada com grade aradora de discos. 
O terreno em sua maior parte é plano e não há desníveis muito acentuados. Anualmente, entre os meses de dezembro e janeiro o terreno sofre alagamento em decorrência das cheias do rio que passa pela propriedade.

O conjunto mecanizado utilizado para a implantação da cultura foi constituído de um trator Massey Ferguson da linha 283, 4x2 TDA, e uma semeadora de precisão modelo de quatro linhas de plantio direto da marca SEED LINE modelo 3705L de 5 linhas de plantio, com disco duplo defasado, dosadores de sementes com discos perfurados, e dosadores de adubo do tipo rosca helicoidal e chassi com 2,75 m de comprimento.

As amostras de solo foram coletadas por meio de um amostrador de solo modelo Uhland no mesmo dia em que o experimento foi conduzido, e retiradas à profundidade de $0 \mathrm{a} 0,2 \mathrm{~m}$ e em número de 23 amostras simples, formando uma amostra composta.

A densidade do solo foi determinada no perfil de 0 a $0,20 \mathrm{~m}$ e foi utilizada como um método indicativo para análise do estado de compactação do solo. No entanto, esse parâmetro não foi interpretado isoladamente, pois varia conforme o solo e em cada faixa de teor de argila, podendo levar a distorções, caso não se atente a esse fato.

O solo apresentou $28,08 \%$ de areia $26,76 \%$ de silte e $45,16 \%$ de argila, sendo classificado como de textura argilosa de acordo com Embrapa (2006). Os demais resultados das análises do solo foram $19,6 \%$ de umidade e $1,07 \%$ e 2,64 g.cm ${ }^{3}$ de densidade do solo.

No Quadro 1 está apresentado o resultado das análises efetuadas nas amostras de solo. As amostras foram analisadas em laboratório da FUNDENOR (Fundação de Desenvolvimento Rural do Norte Fluminense).

Foi utilizada adubação de plantio com adubo de formulação de NPK 4-30-10 aplicando-se 55 $\mathrm{mg} / \mathrm{dm}^{3}(110 \mathrm{~kg} / \mathrm{ha})$. Além da adubação de plantio foi feita adubação de cobertura parcelada em duas vezes com formulado de NK utilizado foi 20-00-25 e aplicou-se $40 \mathrm{mg} / \mathrm{dm}^{3}$ ( $\left.80 \mathrm{~kg} / \mathrm{ha}\right)$.

Para a implantação da cultura do milho, a semeadora de precisão foi regulada para distribuir 5,9 sementes de milho por metro linear, com 5 $\mathrm{cm}$ de profundidade de semeadura e espaçamento entre linhas de plantio de $90 \mathrm{~cm}$. A densidade de plantas utilizada no experimento foi em torno de 65.000 plantas.ha $^{-1}$ e utilizou-se para implantação da cultura sementes de milho hibrido Agroceres.

Foi realizado o teste de germinação de sementes em laboratório conforme as normas específicas estabelecidas para germinação de sementes de milho, propostas pelas Regras para Análise de Sementes (BRASIL, 2009). De acordo com o resultado do teste de germinação, a percentagem média de plântulas normais foi de $89 \%$ e a de sementes germinadas foi de $98 \%$.

Para a avaliação do desempenho da semeadora e da produtividade da cultura, o experimento foi montado seguindo o delineamento em blocos casualizados, com três tratamentos (velocidades) e quatro repetições (blocos) para cada tratamento, totalizando 12 parcelas.

Para a avaliação do desempenho da semeadora de precisão cada bloco foi constituído de três percursos da máquina, e cada percurso foi realizado com uma marcha do trator.

Foram feitas três repetições nas linhas centrais de cada parcela experimental e foram utilizadas três velocidades de deslocamento $-1^{\text {a }}$ simples; $3^{\mathrm{a}}$ reduzida e $4^{\mathrm{a}}$ reduzida, referentes às velocidades aproximadas de 7,0; 5,5 e 4,5 km.h1 , respectivamente, trabalhando-se a $1500 \mathrm{rpm}$ no motor.

A avaliação das plantas foi feita nas linhas centrais. Foram marcadas 10 plantas consecutivas em cada parcela, num total de quatro blocos. Os

Quadro 1. Resultado da análise de solo da área experimental.

\begin{tabular}{|c|c|c|c|c|c|c|c|c|}
\hline Amostra & $\mathrm{pHH}_{2} \mathrm{O}$ & $\mathrm{S}-\mathrm{SO}_{4}$ & $\mathrm{P}$ & K & $\mathrm{Al}$ & MO & $\mathrm{V}$ & $\mathrm{m}$ \\
\hline & & $\mathrm{mg} / \mathrm{dm}^{3}$ & $\mathrm{mg} / \mathrm{dm}^{3}$ & $\mathrm{mg} / \mathrm{dm}^{3}$ & $\mathrm{mg} / \mathrm{dm}^{3}$ & $\mathrm{mg} / \mathrm{dm}^{3}$ & $\%$ & $\%$ \\
\hline Média & 5,3 & 13 & 8,1 & 5865 & 2340 & 20410 & 40 & 10 \\
\hline
\end{tabular}


dados referentes aos caracteres produtivos foram registrados aos 60 e 80 dias após a semeadura.

As variáveis avaliadas relacionadas ao desempenho da máquina foram a patinagem da roda de acionamento da semeadora de precisão, velocidade periférica do disco dosador de sementes, número de sementes, espaçamento entre sementes e profundidade de semeadura.

A patinagem da roda de acionamento da semeadora de precisão foi determinada pela relação entre o número de voltas da roda de acionamento em condição com carga e sem carga, e é dada em $\%$. Cada dado da patinagem foi obtido deslocandose a semeadora até sua roda completar quatro voltas inteiras. A condição de avanço com carga foi calculada pela relação entre a distância percorrida durante a operação de semeadura e o número de voltas percorridas pela roda de acionamento da semeadora. A condição de avanço sem carga foi calculada pela relação entre a distância percorrida pela semeadora em pista asfaltada, condição sem deslizamento, e o número de voltas percorridas. Foram realizadas cinco repetições para sua determinação.

Para determinação da velocidade periférica do disco dosador de sementes utilizou-se velocidades médias de trabalho da semeadora, medida no campo, por meio de um aparelho de GPS modelo Garmin GPSMAP 60CSx, sendo estas velocidades consideradas como a velocidade periférica da roda motriz acionadora, considerando-se a patinagem da roda motriz da semeadora.

Utilizou-se disco de distribuição de sementes de 28 células. A distância entre a célula do disco e seu centro é de $8,75 \mathrm{~cm}$. As engrenagens utilizadas da semeadora de precisão foram de 14-18-18-28 dentes, nesta mesma ordem. O número de dentes da distribuição foi de 40 dentes e do pinhão foi de 10 dentes.

A frequência de trabalho da roda motriz acionadora do sistema de transmissão foi calculada pela relação entre a velocidade periférica da roda de acionamento e o comprimento da mesma. A frequência de cada engrenagem do sistema de transmissão foi calculada pela relação do número de dentes entre cada uma, quando interligadas por corrente. Quando dispostas no mesmo eixo, consideram-se ambas com a mesma frequência. A velocidade periférica do disco dosador de sementes da semeadora foi calculada pelo comprimento da roda de acionamento e a frequência da roda acionadora.

A distribuição longitudinal de sementes foi obtida desenterrando, cuidadosamente, e contandose o número de sementes depositadas em um metro e medindo-se o número e espaçamento entre sementes em um metro com o auxílio de uma trena.

A profundidade de semeadura foi determinada 14 dias após a semeadura, cortando-se a parte aérea das plantas rente ao solo e coletando a semente com o mesocótilo. Utilizou-se uma régua graduada em milímetros para determinar a profundidade de semeadura.

Os parâmetros relacionados ao desenvolvimento da cultura foram altura da planta até o ponto de inserção da última folha, diâmetro do colmo, número de folhas por planta, comprimento e largura da folha, comprimento das espigas com e sem palha, diâmetro das espigas com e sem palha e peso das espigas com e sem palha. Foi feita apenas a avaliação das espigas comerciais.

Para a avaliação dos caracteres produtivos das plantas, foram medidas 10 plantas consecutivas, por parcela em quatro blocos, no estádio R3 grãos leitosos.

A altura de plantas corresponde à distância média, em centímetros, entre a superfície do solo e o ponto de inserção da última folha tomada das 10 plantas da área útil de cada parcela, no florescimento e foi determinada utilizando uma trena graduada em centímetros.

Para a determinação do diâmetro do colmo das plantas, foi utilizado um paquímetro digital de precisão 0,1 milímetro medindo-se no primeiro internódio do colmo, a partir da superfície do solo.

O comprimento de espigas empalhadas e despalhadas foi obtido pelo comprimento médio das 10 espigas provenientes da área útil de cada parcela, tomado em centímetros. O comprimento da espiga foi determinado por meio de uma trena graduada em centímetros.

O diâmetro de espigas empalhadas e despalhadas corresponde ao diâmetro médio, em milímetros, da porção central das espigas comerciais avaliadas. Este foi obtido utilizando-se o mesmo paquímetro utilizado para determinação do diâmetro do colmo, dado em milímetros. 
O peso de espigas comerciais empalhadas e despalhadas foi determinado em todas as espigas comerciais empalhadas da parcela.

Os dados obtidos foram tabulados em planilhas e submetidos à análise de variância pelo teste $\mathrm{F}$ de acordo com o delineamento experimental adotado. As médias foram comparadas pelo teste de Tukey, a 1 e $5 \%$ de probabilidade.

\section{RESULTADOS E DISCUSSÃO}

Os resultados das estimativas da média e coeficiente de variação $(\mathrm{CV})$ das amostras para as variáveis avaliadas relacionadas ao desempenho da máquina serão apresentados nos respectivos quadros a seguir, e estas foram a patinagem da roda de acionamento da semeadora, capacidade efetiva, eficiência de campo, velocidade periférica do disco dosador de sementes, número de sementes por metro linear, espaçamento entre sementes, profundidade de semeadura, comprimento, diâmetro e peso de espigas empalhadas e despalhadas.

No Quadro 2 apresenta-se a análise de variância expressa pelo Teste de F para as variáveis capacidade de campo efetiva, patinagem da semeadora, velocidade do disco dosador de sementes, número de sementes por metro linear, espaçamento entre sementes e profundidade de semeadura em função da velocidade de deslocamento.

De acordo com o que está apresentado no Quadro 2, ocorreu diferença significativa na velocidade periférica do disco dosador, número de sementes por metro e espaçamento entre sementes.

A patinagem da roda de acionamento da semeadora não foi influenciada significativamente pela velocidade, e tiveram médias na marcha referente a velocidade mais rápida de 7,90\% e na referente a velocidade mais lenta de $7,56 \%$. No entanto, este valor está próximo das faixas determinadas por Vale et al. (2008), que encontraram resultados com médias entre 6,7 a $7,7 \%$, respectivamente.

O número de sementes por metro e o espaçamento entre sementes sofreram influência significativa das velocidades de trabalho e estão diretamente ligados à velocidade periférica do disco dosador de sementes. Quanto maior a velocidade do disco, a tendência de ocorrer irregularidades na distribuição de sementes será maior. Portanto, esse fato pode ser observado a partir das médias obtidas no número de sementes por metro e espaçamento entre sementes, em que se observou a melhor e a pior distribuição de sementes (4,91 e 3,91 sementes por metro) nas velocidades menor e maior $\left(4,5\right.$ e $\left.7,0 \mathrm{~km} . \mathrm{h}^{-1}\right)$, respectivamente. Portanto, os resultados justificam teoria descrita por Mantovani et. al. 1999; Vale et al. 2008.

Quanto ao resultado da profundidade de semeadura, esta não sofreu influência da velocidade de deslocamento e suas médias obtidas mostraram que a semeadora depositou sementes bem próximas da profundidade regulada $(5 \mathrm{~cm})$.

O Quadro 3 mostra a percentagem de espaçamentos aceitáveis, duplos e falhos, para as velocidades de trabalho 4,$5 ; 5,5$ e $7,0 \mathrm{~km} \cdot \mathrm{h}^{-1}$.

De acordo com as normas técnicas da ABNT

Quadro 2. Síntese da análise de variância para os parâmetros, patinagem da semeadora (S), velocidade do disco dosador de sementes (Vd), número de sementes por metro linear (NSm), espaçamento entre sementes (EES), profundidade de semeadura (Prof).

\begin{tabular}{lccccc}
\hline Velocidade & $\mathrm{S}$ & $\mathrm{Vd}$ & $\mathrm{NSm}$ & $\mathrm{EES}$ & Prof \\
\hline $\mathrm{km} \cdot \mathrm{h}^{-1}$ & $\%$ & $\mathrm{~m} \cdot \mathrm{s}^{-1}$ & & $\mathrm{~cm}$ & $\mathrm{~cm}$ \\
\hline 4,5 & $7,56 \mathrm{a}$ & $0,37 \mathrm{~b}$ & $4,56 \mathrm{a}$ & $21,93 \mathrm{~b}$ & $4,86 \mathrm{a}$ \\
5,5 & $8,49 \mathrm{a}$ & $0,46 \mathrm{~b}$ & $4,91 \mathrm{a}$ & $20,37 \mathrm{~b}$ & $4,95 \mathrm{a}$ \\
7,0 & $7,90 \mathrm{a}$ & $0,55 \mathrm{a}$ & $3,91 \mathrm{~b}$ & $25,58 \mathrm{a}$ & $4,65 \mathrm{a}$ \\
\hline C.V $(\%)$ & 35,109 & 4,423 & 12,335 & 12,161 & 12,562 \\
\hline
\end{tabular}

Médias seguidas de pelo menos uma mesma letra não diferem estatisticamente pelo teste de Tukey, em nível de 5\% de probabilidade. * significativo a $5 \%$ de probabilidade; ** significativo a $1 \%$; ${ }^{\text {ns }}$ não significativo. 
Quadro 3. Avaliação de espaçamentos aceitáveis, duplos e falhos para as velocidades estudadas.

\begin{tabular}{lccc}
\hline Velocidade & \multicolumn{3}{c}{ Média de espaçamentos } \\
\hline $\mathrm{km} \cdot \mathrm{h}^{-1}$ & Aceitáveis & Duplos & Falhos \\
\hline 4,5 & $76,17 \mathrm{a}$ & $6,52 \mathrm{a}$ & $20,77 \mathrm{a}$ \\
5,5 & $75,55 \mathrm{a}$ & $4,86 \mathrm{a}$ & $19,58 \mathrm{a}$ \\
7,0 & $75,5 \mathrm{a}$ & $0,00 \mathrm{a}$ & $24,44 \mathrm{a}$ \\
\hline C.V $(\%)$ & 6,75 & 23,02 & 29,03
\end{tabular}

Médias seguidas de pelo menos uma mesma letra não diferem estatisticamente pelo teste de Tukey, em nível de 5\% de probabilidade.

Quadro 4. Síntese da análise de variância para os parâmetros altura da planta (APL), diâmetro do colmo (DC), numero de folhas por planta (NFPL), comprimento da folha (CF) e largura da folha (LF) aos 60 e 80 dias após semeadura.

\begin{tabular}{ccccc}
\hline $\begin{array}{c}\text { Velocidade } \\
\mathrm{km} \cdot \mathrm{h}^{-1}\end{array}$ & $\begin{array}{c}\text { APL } \\
\mathrm{cm}\end{array}$ & $\begin{array}{c}\text { DC } \\
\mathrm{mm}\end{array}$ & $\begin{array}{c}\mathrm{CF} \\
\mathrm{mm}\end{array}$ & $\begin{array}{c}\mathrm{LF} \\
\mathrm{mm}\end{array}$ \\
\hline 4,5 & $120,31 \mathrm{a}$ & $25,71 \mathrm{a}$ & $100,80 \mathrm{~b}$ & $9,28 \mathrm{a}$ \\
5,5 & $118,61 \mathrm{a}$ & $24,71 \mathrm{a}$ & $101,24 \mathrm{~b}$ & $9,17 \mathrm{a}$ \\
7,0 & $122,48 \mathrm{a}$ & $24,68 \mathrm{a}$ & $104,22 \mathrm{a}$ & $9,18 \mathrm{a}$ \\
\hline DAP & & & & \\
\hline 60 & $60,00 \mathrm{~b}$ & $27,33 \mathrm{a}$ & $99,38 \mathrm{~b}$ & $9,01 \mathrm{~b}$ \\
\hline 80 & $180,93 \mathrm{a}$ & $22,74 \mathrm{~b}$ & $104,79 \mathrm{a}$ & $9,41 \mathrm{a}$ \\
\hline C.V $(\%)$ & 12,091 & 15,360 & 7,909 & 8,522 \\
\hline
\end{tabular}

Médias seguidas de pelo menos uma mesma letra não diferem estatisticamente pelo teste de Tukey, ao nível de 5\% de probabilidade.

(1994) os espaçamentos entre plantas (EEP) foram analisados da seguinte forma: espaçamentos duplos os valores que são menores que 0,5 .XREF, espaçamentos aceitáveis valores que se encontram dentro dos limites 0,5 a 1, 5.XREF e espaçamentos falhos os valores maiores do que 1,5.XREF. O espaçamento de referência foi de $16,9 \mathrm{~cm}$ entre plantas (sementes). Os resultados não foram significativos para a média de espaçamentos entre sementes.

Apenas na velocidade de $7,5 \mathrm{~km} \cdot \mathrm{h}^{-1}$ não houve sementes múltiplas (espaçamento duplo entre sementes), possivelmente pelo fato de com uma velocidade mais rápida não ter tido tempo o suficiente para preenchimento de mais de uma semente por furo no disco dosador de sementes.

No Quadro 4 apresenta-se a análise de variância para as variáveis altura da planta, diâmetro do colmo, número de folhas por planta, comprimento da folha e largura da folha em função da velocidade de deslocamento. A sigla DAP representa o número de dias após semeadura.

De acordo com o que está apresentado no Quadro 4, ocorreu influência significativa da velocidade apenas no comprimento da folha, onde se observou maior comprimento de folhas $(104,22 \mathrm{~cm})$ na maior velocidade de deslocamento $\left(7,0 \mathrm{~km} \cdot \mathrm{h}^{-1}\right)$. No entanto, pode-se dizer que, essa influência caberia no aspecto nutricional da folha, já que a relação entre esta variável e a sua largura resulta na área foliar.

Em relação aos dias após a germinação, com as amostras coletadas aos 60 e 80 dias após a 
Quadro 5. Síntese da análise de variância para os parâmetros comprimento de espigas com palha (CCP), diâmetro de espigas com palha (DCP), peso de espigas com palha (PCP), comprimento de espigas sem palha (CSP), diâmetro de espigas sem palha (DSP) e peso de espigas sem palha (PSP).

\begin{tabular}{ccccccc}
\hline $\begin{array}{c}\text { Velocidade } \\
\mathrm{km} \cdot \mathrm{h}^{-1}\end{array}$ & DCP & CCP & PCP & DSP & CSP & PSP \\
\hline 4,5 & $\mathrm{~mm}$ & $\mathrm{~cm}$ & $\mathrm{~g}$ & $\mathrm{~mm}$ & $\mathrm{~cm}$ & $\mathrm{~g}$ \\
\hline 5,5 & $31,38 \mathrm{a}$ & $60,05 \mathrm{a}$ & $397,85 \mathrm{a}$ & $18,74 \mathrm{a}$ & $4633 \mathrm{a}$ & $242,39 \mathrm{a}$ \\
7,0 & $31,09 \mathrm{a}$ & $59,32 \mathrm{a}$ & $371,59 \mathrm{a}$ & $18,73 \mathrm{a}$ & $45,62 \mathrm{a}$ & $213,46 \mathrm{a}$ \\
\hline $\mathrm{C} . \mathrm{V}(\%)$ & $30.69 \mathrm{a}$ & $60,72 \mathrm{a}$ & $419,59 \mathrm{a}$ & $25,38 \mathrm{a}$ & $46,06 \mathrm{a}$ & $236,21 \mathrm{a}$ \\
\hline
\end{tabular}

Médias seguidas de pelo menos uma mesma letra não diferem estatisticamente pelo teste de Tukey, ao nível de $5 \%$ de probabilidade.

semeadura, pode-se observar que a altura da planta foi em média 60 e 180,93 cm, respectivamente. Os dados estão bem próximos aos encontrados por Rodrigues et al. (2012), que obtiveram 1,85 m de altura da planta aos 100 dias após a semeadura, e superiores aos encontrados por Pereira et al. (2009) em trabalho realizado com cultivares de milho doce o em que se observou valores de altura de plantas com médias de $1,68 \mathrm{~m}$.

Em relação ao diâmetro dos colmos, os resultados encontrados mostram que foram bem próximos aos encontrados por Rodrigues et al. (2012), que obtiveram médias entre 22,9 e 23,9 mm de diâmetro do colmo. Já Stacciarini et al. (2010), obtiveram média de $25,3 \mathrm{~mm}$ de diâmetro de colmo, em trabalho realizado com $60.00075 .000 \mathrm{e}$ 90.000 plantas por hectare, com espaçamento entre linhas de 0,9 e $0,45 \mathrm{~m}$.

No Quadro 5 está apresentada a análise de variância expressa pelo Teste de $\mathrm{F}$ para as variáveis diâmetro, comprimento e peso de espigas verdes com palha e diâmetro, comprimento, peso de espigas verdes sem palha em função da velocidade de deslocamento.

De acordo com os resultados apresentados no Quadro 5, pode-se dizer que não houve influência significativa da velocidade de trabalho nos caracteres diâmetro, comprimento e peso de espigas verdes com palha e diâmetro, comprimento, peso de espigas verdes sem palha.

De acordo com Rocha (2008), em trabalho realizado com 50.000 plantas por hectare, este obteve resultados com média de $64,5 \mathrm{~mm}$ de diâmetro de espigas verdes empalhadas e $44 \mathrm{~mm}$ de diâmetro de espigas despalhadas. Em nenhum dos três tratamentos, as médias do comprimento de espigas com e sem palha foram menores ou iguais aos dos resultados encontrados pelo autor citado anteriormente. Uma possível causa para esses resultados é o fato de se considerar que a densidade de semeadura interferiu na competição das plantas por nutrientes e água. Desse modo, pode haver queda no peso e, consequentemente na produtividade da cultura.

\section{CONCLUSÕES}

- Embora os resultados da profundidade de semeadura terem sido satisfatórios, o projeto da máquina precisa ser melhorado quanto às regulagens da profundidade de deposição de sementes (máximo de $5 \mathrm{~cm}$ ).

- Recomenda-se, o uso deste modelo de máquina, com esta regulagem de engrenagens na velocidade de deslocamento de $4,5 \mathrm{~km} \cdot \mathrm{h}^{-1}$.

\section{AGRADECIMENTOS}

À Coordenação de Aperfeiçoamento de Pessoal de Nível Superior (Capes) pela bolsa concedida e à Fundação de Amparo à Pesquisa do Estado do Rio de Janeiro (Faperj) pelo auxílio financeiro a equipe de trabalho. 


\section{REFERÊNCIAS BIBLIOGRÁFICAS}

ASSOCIAÇÃO BRASILEIRA DE NORMAS TÉCNICAS. Projeto de norma 12:02.06-004 Semeadora de precisão - Ensaio de laboratório. São Paulo, 21p. 1994.

BRASIL. Ministério da Agricultura, Pecuária e Abastecimento. Regras para análise de sementes / Ministério da Agricultura, Pecuária e Abastecimento. Secretaria de Defesa Agropecuária. - Brasília : Mapa/ACS. 399p. 2009.

CARDOSO, M.J.; SILVA, A.R.; GUIMARÃES, L.J.M.; PARENTONI, S.N.; SETUBAL, J.W. Produtividade e espiga verde de milho sob diferentes níveis de nitrogênio. Horticultura Brasileira, Brasília, DF, v.28, n.2, S3786-S3789, 2010.

CONAB - COMPANHIA NACIONAL DE ABASTECIMENTO. Acompanhamento de safra brasileira: grãos: intenção de plantio, primeiro levantamento, outubro 2012. Brasília: Conab, 2012.

EMPRESA BRASILEIRA DE PESQUISA AGROPECUÁRIA - EMBRAPA. Centro Nacional de Pesquisa de Solos. Sistema brasileiro de classificação de solos, 2 ed. Rio de Janeiro, 306p, 2006.

MANTOVANI, E.C.; MANTOVANI, B.H.M.; CRUZ, I.; MEWES, W.L.C.; OLIVEIRA, A.C. Desempenho de dois sistemas distribuidores de sementes utilizados em semeadoras de milho. Pesquisa Agropecuária Brasileira, Brasília, v.34, n.1, p.93-98, 1999.

PEREIRA FILHO, I.A.P.; OLIVEIRA, A.C.; CRUZ, J.C. Milho verde: espaçamentos, densidades de plantas, cultivares e épocas de semeadura, influenciando o rendimento e algumas características de espigas comerciais.
IN: CONGRESSO NACIONAL DE MILHO E SORGO, 22, 1998, Recife. Anais... Recife: EMBRAPA, 1998. p.255.

PEREIRA, A.F.; MELO, P.G.S.; PEREIRA, J.M.; Assunção, A.; NASCIMENTO, A.R.; XIMENES, P.A. Caracteres agronômicos e nutricionais de genótipos de milho doce. Bioscience Journal, Uberlândia, v.25, n.1, p.104-112, 2009.

ROCHA, D.R.. Desempenho de cultivares de milho-verde submetidas a diferentes populações de plantas em condições de irrigação. 2008. 106p. Tese (Doutorado em Agronomia). Faculdade de Ciências Agrárias e Veterinárias - UNESP, Câmpus de Jaboticabal. São Paulo, 2008.

RODRIGUES,T.R.D.;BROETTO,L.; OLIVEIRA, P.S.R.; ,RUBIO, F.. Desenvolvimento da cultura do milho submetida a fertilizantes orgânicos e minerais. Biosciense Journal, Uberlândia, v.28, n.4, p.509-514, 2012.

SILVA, F.M.; COAN, O.; NATALE, W. Influência da profundidade de semeadura com e sem uso de sulcador na cultura de milho (Zea mays L.). IN: CONGRESSO BRASILEIRO DE ENGENHARIA AGRÍCOLA, 22, 1993, Ilhéus. Anais... Ilhéus: SBEA/CEPLAC, 1993. p.1438-1452.

STACCIARINI, T.C.V.; CASTRO, P.H.C.; BORGES, M.A.; GUERIN, H.F.; MORAES, P.A.C.; GOTARDO, M.. Avaliação de caracteres agronômicos da cultura do milho mediante a redução do espaçamento entre linhas e aumento da densidade populacional. Revista Ceres, Viçosa, v.57, n.4, p.516-519, 2010.

VALE, W.G.; GARCIA, R.F.; THIEBAUT, J.T.L.; AMIM, R.T.; TOURINO, M.C.C. Desempenho e dimensionamento amostral para avaliação de uma semeadora-adubadora em plantio direto e convencional. Acta Scientiarum Agronomy, v.30, p.441-448, 2008. 